\title{
Temporal and Spatial Differentiations in Environmental Governance
}

\author{
Benhong Peng ${ }^{1,2, *}$, Yue $\mathrm{Li}^{3, *}$, Guo Wei ${ }^{4}$ and Ehsan Elahi ${ }^{5}$ \\ 1 Research Base of Socialism with Chinese Characteristics Theory System and Science, \\ Nanjing University of Information Science and Technology, Nanjing 210044, China \\ 2 School of Management Science and Engineering, Nanjing University of Information Science \& Technology, \\ Nanjing 210044, China \\ 3 School of Management, Jiangsu University, Zhenjiang 212001, China \\ 4 Department of Mathematics \& Computer Science, University of North Carolina at Pembroke, \\ Pembroke, NC 28372, USA; guo.wei@uncp.edu \\ 5 School of Business, Nanjing University of Information Science and Technology, Nanjing 210044, China; \\ ehsanelahi@nuist.edu.cn \\ * Correspondence: 002426@nuist.edu.cn (B.P.); 2211810039@stmail.ujs.edu.cn (Y.L.); \\ Tel.: +86-180-5102-9451 (B.P.); +86-182-6261-8781 (Y.L.)
}

Received: 9 September 2018; Accepted: 9 October 2018; Published: 12 October 2018

check for updates

\begin{abstract}
With the general degradation of environmental carrying capacity in recent years, many developing countries are facing with the dual task of economic development and environmental protection. To explore the issue of urban environmental governance, in this research, we establish a Data Envelopment Analysis (DEA) model to investigate the environmental governance regarding temporal and spatial efficiency. Further, we deconstruct environmental governance efficiency into comprehensive efficiency, pure technical efficiency, and scale efficiency and develop a Tobit model to analyze the influencing factors affecting urban environmental governance efficiency. In addition, the above DEA, Tobit model, and deconstruction of efficiency have been applied to study environmental governance efficiency for the Yangtze River urban agglomeration. Findings include: (1) The gap in environmental governance efficiency between cities is highly noticeable, as the highest efficiency index is 0.934 , the lowest is only 0.246 , and the comprehensive efficiency index has fallen sharply from 0.708 to 0.493 in the past 10 years; (2) Environmental governance efficiency is basically driven by technological progress, while the scale efficiency change index is the main driver of the technological progress change index; (3) For environmental governance efficiency, urbanization and capital openness are irrelevant factors, economic level and urban construction are unfavorable factors, and industrial structure and population density are favorable factors. These findings will help urban agglomerations to effectively avoid the adverse effects of environmental governance efficiency in economic development, and achieve a coordinated development of urban construction and environmental governance.
\end{abstract}

Keywords: Yangtze River urban agglomeration; environmental governance; DEA model; Malmquist; Tobit model

\section{Introduction}

Accompanying the accelerated advancement of the global economy, the problem of urban environmental governance has become the focus of all countries. In fact, as early as 1992, the World Organization for Sustainable Development had already targeted the problem by proposing the concept of "environmental efficiency" to measure the environmental costs of urban economic development. 
In the context of global attention to environmental issues, achieving environment-friendly economic growth is imperative for many fast developing countries. In China, accompanied by the astonishing development of urban industrialization, numerous urban agglomerations of different sizes have formed so far, such as the Yangtze River urban agglomeration or the Pearl River urban agglomeration. However, under the condition of limited environmental carrying capacity, the environmental problems caused by both the population aggregation and the industrial development are constantly increasing the pressure of environmental governance in urban agglomerations and have become a prominent social issue that affects the production and life of urban residents.

Consequently, studying the environmental governance of urban agglomeration is an important exploration of environmental issues in the process of urbanization. The analysis of the environmental conditions of the Yangtze River, which is the longest river system in the country, crossing 31 provinces, is of great significance to other urban agglomerations facing the same problems.

At present, research on environmental governance at home and abroad is mainly focused on:

(1) Environmental Governance Efficiency (EGE)

Gan and Wang [1] (2013) used the Data Envelopment Analysis (DEA) model, and Malmquist index to calculate the EGE and dynamic change of the Yangtze River Delta cities, a coastal area in eastern China, 51,000 square kilometers that includes Nanjing, Zhenjiang, Yangzhou, Taizhou, Changzhou, Wuxi, Suzhou, Nantong, with a population of 50 million. They found that the EGE appeared generally higher and fluctuating upward in the Yangtze River Delta.

Zaim O [2] (2000) used nonparametric techniques to measure the EGE of Organisation for Economic Co-operation and Development, formulated an EGE index, and compared pollution control across countries. The results showed that strict limit on carbon emissions will lead to output losses. Mandal, Madheswaran [3] (2007) used DEA to measure the EGE of India in a joint production framework. The results showed that the cement industry may expand the desired production and shrink the unfavorable output in the face of environmental regulation. Van Leeuwen, Koop, and Sjerps [4] (2016) made a baseline assessment of water resource governance in Europe and found that cities in transitional and developing countries are prone to water risk. Tang, Zhang, and Liu [5] (2016) used the slackness measurement (SBM) poor model to analyze the efficiency of environmental regulation. The results showed that environmental regulation efficiency presented a "polarization" effect and the environmental regulation total factor productivity had a clear "aggregation" effect in China.

\section{(2) Environmental governance research methods}

Reinhard et al. [6] (2000) used the Stochastic Frontier Approach and Data Envelopment Analysis (DEA) to estimate the comprehensive EGE measures and compared the two methods. The results showed that DEA is more suitable for calculating the EGE scores of all specifications. Luo [7] (2012) proposed an EGE evaluation method based on slack variables, which was applied to the efficiency of industrial environment in China. It was found that about two-thirds of the decision-making units were not effective. Tang et al. [8] (2012) constructed a low carbon manufacturing evaluation index system and proposed evidence for industrial policy innovation based on this evaluation system. Tu and Qiu [9] (2013) based their research on the DEA-based directional distance function method to examine China's industrial EGE and found that environmental technology efficiency assessed by traditional techniques underestimated the EGE. Kuosmanen and Entertainer [10] (2015) evaluated how Data Envelopment Analysis aggregated environmental pressures into a single environmental damage index by assessing the EGE of urban road transport in eastern Finland. Koop [11] (2017) analyzed the water, waste, and climate change challenges of cities, and used an empirical method to achieve consistent comparisons between cities and then proposed governance options.

(3) Environmental governance policy 
Gunningham [12] (2009) examined the relationship between old and new governance from the perspective of three Australian case studies, and revealed the importance of the state in the "shadow of hierarchy". Tang [13] (2012) pointed out the challenges faced by China's low-carbon manufacturing industry and proposed related countermeasures through comparison of China's energy consumption with other countries. Bruce and William [14] (2014) reviewed the dynamic change in China's local environmental governance and proposed solutions to the problems of "policy implementation gap" and "participation gap". Kitagawa, Geng [15] (2017) has studied China's environmental governance policy pipeline since 1979, and believes that implementing environmental governance policies should be centered on local governments. From the four aspects of legal, management, governance mechanism, and policy, Tang [16] (2017) combed the refined governance system formed by Japan in the process of environmental governance, and proposed the improvement path of China's environmental governance. The above scholars' research methods are relatively simple, failing to fully reflect the status of efficiency development. The area of research objects is relatively extensive; the research on urban agglomerations as an object and urban EGE data as indicators is not sufficient, and the study of EGE in large regions does not reflect the heterogeneity of regional development. Furthermore, it lacks of space-time analysis of efficiency differences and the study of the trend of efficiency development.

This article uses data from 8 cities of the Yangtze River urban agglomeration from 2007 to 2016 to build a DEA model, for calculating the efficiency of environmental management. On one hand, it comprehensively analyzes the environmental governance of the Yangtze River urban agglomeration; by contrast, it also deconstructs the EGE to compare and analyze the spatial and temporal differences in EGE among cities, and further discusses relevant factors affecting the EGE of the Yangtze River urban agglomeration, expecting to fill the gap in space-time differentiation study and to provide useful ideas for the governance of urban agglomerations.

In the remainder of this article, the contents are arranged in the following way: Section 2 introduces the DEA model and data sources, and establishes an EGE indicator system. Section 3 analyzes the difference of EGE between cities within the Yangtze River urban agglomeration from the perspective of time and space, and uses the Malmquist exponential decomposition to investigate the impact of various indicators on EGE. Section 4 uses the Tobit regression model to analyze the magnitude and impact of important factors affecting the EGE of cities in the Yangtze River urban agglomeration. In Section 5, we summarize the environmental management efficiency of the Yangtze River urban agglomeration and give relevant suggestions.

\section{Research Methodology}

In this section, we study the rationality of the data envelopment analysis (DEA) method for our problem and examine the data sources. Subsequently, we construct an EGE index system based on the ecological status regarding the Yangtze River urban agglomeration for exploring influencing factors of EGE.

\subsection{DEA Model}

DEA, or data envelopment analysis, is a research method proposed by well-known American researchers Charnes, Copper, and Rhodes in 1978 to evaluate efficiency among samples [17] (Charnes, Cooper, Rhodes, 1982). When using the DEA model for efficiency calculation, an indicator system and a decision unit [18,19] (DU) (Fare and Grosskopf, 1986; Huppes and Ishikawa, 1986) (Decisio Making Units, DMU) should be established: If efficiency is 1, the output of the DU is on the frontier boundary, which indicates that the input is effective; if efficiency is less than 1, the output of the DU is at a distance from the frontier boundary, which means that there is still some distance between the effect of investment and the ideal result. Specifically, DEA is a model that uses mathematics planning to establish evaluations, determines relatively effective production frontiers, and projects each DU onto the production frontier. The relative effectiveness of each DU is compared by the 
distance from the DU to the production frontier [20] (Wang, et al., 2010). The specific model formula is as follows:

$$
\begin{gathered}
\rho^{*}=\operatorname{Min} \frac{1-\frac{1}{m} \sum_{i=1}^{m} \frac{\bar{s}_{r}}{x_{i o}}}{1+\frac{1}{s_{1}+s_{2}}\left(\sum_{r=1}^{x_{1}} \frac{s^{g} g_{r}}{y^{g} r_{r o}}+\sum_{r=1}^{x_{2}} \frac{s^{b} y_{r}}{b_{r o}}\right),} \\
x_{o}=X \lambda+\bar{s}, \\
y^{g}=Y^{g} \lambda-s^{g}, \\
y^{b}=Y^{b} \lambda+s^{b}, \\
\bar{s} \geq 0, s^{g} \geq 0, s^{b} \geq 0, \lambda \geq 0
\end{gathered}
$$

where $x$ is a single input to the production unit, $X$ is the input vector of the production unit, $\mathrm{m}$ is the quantity of production inputs $x, y$ is a single output, and $Y$ is the output vector of the production unit. $\rho^{*}$ is the efficiency value, $\bar{S}$ stands for the amount of excess redundancy, $S_{r}^{g}$ means that the expected output is insufficient, $S_{r}^{b}$ stands for an excess surplus of an undesired output, and $\lambda$ denotes the weight of input and output.

When $\rho^{*}=1$ and $\bar{S}=0$, or $S_{r}^{g}=0$, or $S_{r}^{b}=0$, the DMU is an effective unit of EGE.

When $\rho^{*}=1$ and $\bar{S} \neq 0$, or $S_{r}^{g} \neq 0$, or $S_{r}^{b} \neq 0$, it is a weakly effective unit, that is, while it reduces the input of redundant production unit $\bar{S}$, the output of $y_{0}$ does not change.

When $0 \leq \rho^{*}<1$, it is an invalid unit of EGE, that is, reducing the original input $\rho^{*}$ can leave the production unit $y_{0}$ output unchanged. If the $\mathrm{DMU}$ is improved to be an effective unit, it requires some improvements in input, expectation, and unintended output.

\subsection{Data Sources and Indicators Selection}

The data used in this paper come from Jiangsu Environmental Statistics Annual Report (2008-2017), Environmental Status Bulletin (2007-2016), Environmental Statistical Yearbook (2008-2017), and Statistical Yearbook (2008-2017). We selected 80 pairs of environment-related data from 2007 to 2016 for the DEA model, and 5 indicators from each set of data.

At present, urban environmental governance is dominated by the governments in different administrative regions, and environmental governance in each region is relatively independent. Therefore, the environmental governance process in each administrative region of the Yangtze River urban agglomeration can be regarded as a DU (Fare R, 1986). The environmental governance economic investment is the input of DMU. The EGE is taken as the output of DMU. The EGE is determined by the intended output and unintended output, both caused by the input of environmental governance. Since DEA theory requires that the number of indicators between input and output is less than or equal to half the total number of DMUs in the DU [21] (Guo and Zheng, 2009), we selected the environmental capital investment as the input variable, GDP as the expected output index, and the regional emissions, waste water discharge, and unprocessed industrial solid waste as unintended output indicators, for the following considerations:

1. They have sufficient literature support.

References Gai et al. (2014), Li Min (2017), Wu H Q et al. (2014) used these five indicators to construct an evaluation system for environmental governance efficiency, which verified the rationality of these five indicators.

2. They are representative.

Capital investment is the most important investment in environmental protection, and economic level is an important indicator of efficiency. Waste water and solid waste are the main sources of environmental pollution. Therefore, we used GDP as the expected output, and used the waste water, waste gas, and solid waste as undesired outputs. 
Subsequently, a three-level, three-dimensional index evaluation system was formed (Table 1). At the same time, the urbanization level, industrial structure, economic development level, urban construction, population density, and capital openness index were selected to study the influencing factors of EGE for the Yangtze River urban agglomeration. The descriptive statistical characteristics of input and output are shown in Table 2.

Table 1. Indicator system for Environmental Governance Efficiency (EGE) of the Yangtze River urban agglomeration.

\begin{tabular}{|c|c|c|c|c|}
\hline $\begin{array}{l}\text { Comprehensive } \\
\text { Layer }\end{array}$ & & Target Layer & Indicator Layer & Literature Basis \\
\hline \multirow{5}{*}{$\begin{array}{l}\text { Yangtze River City } \\
\text { Group EGE Index }\end{array}$} & Input indicators & Capital investment & $\begin{array}{l}\text { Total investment in } \\
\text { environmental protection }\end{array}$ & \multirow{5}{*}{$\begin{array}{c}\text { Gai et al. [22] (2014) } \\
\text { Li Min [23] (2017) } \\
\text { Wu H Q et al. [24] (2014) }\end{array}$} \\
\hline & \multirow{4}{*}{ Output indicators } & Expected output & GDP & \\
\hline & & \multirow{3}{*}{ Undesired output } & Exhaust gas emissions & \\
\hline & & & Wastewater discharge & \\
\hline & & & Solid waste untreated & \\
\hline
\end{tabular}

Table 2. Descriptive statistical characteristics of input-output variables in 2007-2016.

\begin{tabular}{ccccccc}
\hline Variable Type & Specific Variable & Unit & $\begin{array}{c}\text { Maximum } \\
\text { Value }\end{array}$ & $\begin{array}{c}\text { Minimum } \\
\text { Value }\end{array}$ & $\begin{array}{c}\text { Average } \\
\text { Value }\end{array}$ & $\begin{array}{c}\text { Standard } \\
\text { Deviation }\end{array}$ \\
\hline Input indicator & Total investment & 108 yuan & 641.23 & 10.12 & 116.33 & 130.63 \\
\hline \multirow{3}{*}{ Output indicator } & GDP & 108 yuan & 15475.09 & 1201.82 & 5027.89 & 3272.20 \\
\cline { 2 - 7 } & Exhaust gas emissions & 108 cubic meter & 15161.3 & 0.24 & 46.78 & 3544.85 \\
\cline { 2 - 7 } & Waste water discharge & 108 ton & 7.46 & 0.56 & 2.53 & 1.75 \\
\cline { 2 - 7 } & Solid waste untreated & 104 ton & 501.85 & 839 & 4122.76 & 74.34 \\
\hline
\end{tabular}

\section{EGE for the Yangtze River Urban Agglomeration}

To grasp the current status of EGE for the Yangtze River urban agglomeration and the impact of various indicators on EGE, we used DEAP 2.1 (University of Queensland, Brisbane, Australia) and OpenGeoDa software tools (University of Chicago, Chicago, IL, USA) to analyze the spatial differences and dynamic evolution of the Yangtze River urban agglomeration from the perspective of time and space, and then the Malmquist Index Decomposition was employed to explore the relationship between each index and the EGE.

\subsection{The Temporal and Spatial Analysis of EGE for the Yangtze River Urban Agglomeration}

Before analyzing the spatial and temporal differentiation of the environmental management efficiency for the Yangtze River urban agglomeration, we started with an overall analysis of EGE.

\subsubsection{Overview of the EGE}

According to the results produced from DEAP 2.1, as shown in Table 3, the overall EGE of the cities in the Yangtze River urban agglomeration is low. In terms of average values, the EGE of Nanjing, Changzhou, Wuxi, and Zhenjiang is relatively high, with the efficiency indices being 0.934, 0.849, 0.742 , and 0.698 , respectively, while the EGE for Yangzhou, Suzhou, Taizhou, and Nantong is relatively low, with the efficiency indices of $0.423,0.371,0.353$, and 0.264 , respectively. This shows a maximum difference of 0.67 in the index, between Nanjing (0.934) and Nantong (0.264), which implies that the EGE of the Yangtze River urban agglomeration is very different by location, and this is not contributive to the co-development of urban agglomerations. 
Table 3. Results of EGE for the Yangtze River urban agglomeration from 2007 to 2016.

\begin{tabular}{cccccccccccc}
\hline DMU & $\mathbf{2 0 0 7}$ & $\mathbf{2 0 0 8}$ & $\mathbf{2 0 0 9}$ & $\mathbf{2 0 1 0}$ & $\mathbf{2 0 1 1}$ & $\mathbf{2 0 1 2}$ & $\mathbf{2 0 1 3}$ & $\mathbf{2 0 1 4}$ & $\mathbf{2 0 1 5}$ & $\mathbf{2 0 1 6}$ & Average \\
\hline Nanjing & 1.00 & 0.84 & 1.00 & 1.00 & 0.79 & 1.00 & 0.70 & 1.00 & 1.00 & 1.00 & 0.93 \\
Zhenjiang & 1.00 & 0.66 & 0.49 & 0.62 & 0.30 & 0.34 & 1.00 & 0.79 & 0.75 & 1.00 & 0.69 \\
Yangzhou & 0.87 & 0.29 & 0.44 & 0.38 & 0.69 & 0.39 & 0.24 & 0.21 & 0.15 & 0.52 & 0.42 \\
Taizhou & 0.48 & 0.36 & 0.32 & 0.33 & 0.54 & 0.51 & 0.28 & 0.23 & 0.17 & 0.25 & 0.35 \\
Changzhou & 1.00 & 1.00 & 1.00 & 0.44 & 1.00 & 1.00 & 1.00 & 0.88 & 0.70 & 0.45 & 0.84 \\
Wuxi & 0.65 & 0.59 & 1.00 & 1.00 & 1.00 & 1.00 & 1.00 & 0.44 & 0.31 & 0.42 & 0.74 \\
Suzhou & 0.38 & 1.00 & 0.41 & 0.45 & 0.34 & 0.40 & 0.24 & 0.20 & 0.14 & 0.12 & 0.37 \\
Nantong & 0.27 & 0.19 & 0.31 & 0.32 & 0.24 & 0.71 & 0.20 & 0.13 & 0.09 & 0.13 & 0.26 \\
\hline
\end{tabular}

\subsubsection{Research on Time Differentiation of EGE}

The EGE is deconstructed into three parts: Comprehensive efficiency (CRSTE), pure technical efficiency (VRSTE), and scale efficiency (SE). CRESTE (comprehensive efficiency) is used to measure whether environmental governance meets the overall requirements and achieves maximum economic and social benefits; VRSTE (pure technical efficiency) represents the maximum output that a decision-making unit can achieve under a given input. It is used to measure the magnitude of the effect on the output unit due to management and technology factors; SE (scale efficiency) examines whether the decision-making units are operating at the most appropriate scale of investment under certain conditions of technology. By calculating CRSTE, we can know the overall environmental governance efficiency of Jiangsu Province. By calculating VRSTE and SE, we can judge the influence of technology and scale on the governance efficiency in the environmental governance process of Jiangsu Province. The average data of the three parts from 2007 to 2016 are selected for differential analysis (Table 4), and Figure 1 is plotted to analyze the overall temporal efficiency of the Yangtze River urban agglomeration. The study finds that the overall EGE of the Yangtze River urban agglomeration is in the upper middle level, and there are problems of excessive resource input or serious shortage of output. In 2007, the EGE reached a maximum, and afterwards the efficiency index gradually decreased. From 2012, the EGE index began to decrease rapidly. The decline indicates that a rapid development of the city's economic level may have caused some negative impact on the environment. In addition, the SE (0.822) is larger than the VRSTE (0.76), which in turn is larger than the CRSTE (0.6), and pure technological efficiency is similar to the curve of changes in CRSTE.

Table 4. The average of comprehensive efficiency (CRSTE), pure technical efficiency (VRSTE), and scale efficiency (SE) of the environmental management in the Yangtze River urban agglomeration from 2007 to 2016.

\begin{tabular}{cccc}
\hline Year & CRSTE & VRSTE & SE \\
\hline $\mathbf{2 0 0 7}$ & 0.70 & 0.85 & 0.83 \\
$\mathbf{2 0 0 8}$ & 0.61 & 0.70 & 0.84 \\
$\mathbf{2 0 0 9}$ & 0.62 & 0.71 & 0.87 \\
$\mathbf{2 0 1 0}$ & 0.64 & 0.74 & 0.86 \\
$\mathbf{2 0 1 1}$ & 0.60 & 0.78 & 0.77 \\
$\mathbf{2 0 1 2}$ & 0.67 & 0.83 & 0.80 \\
$\mathbf{2 0 1 3}$ & 0.58 & 0.74 & 0.80 \\
$\mathbf{2 0 1 4}$ & 0.48 & 0.65 & 0.78 \\
$\mathbf{2 0 1 5}$ & 0.48 & 0.58 & 0.76 \\
$\mathbf{2 0 1 6}$ & 0.49 & 0.66 & 0.81 \\
\hline
\end{tabular}




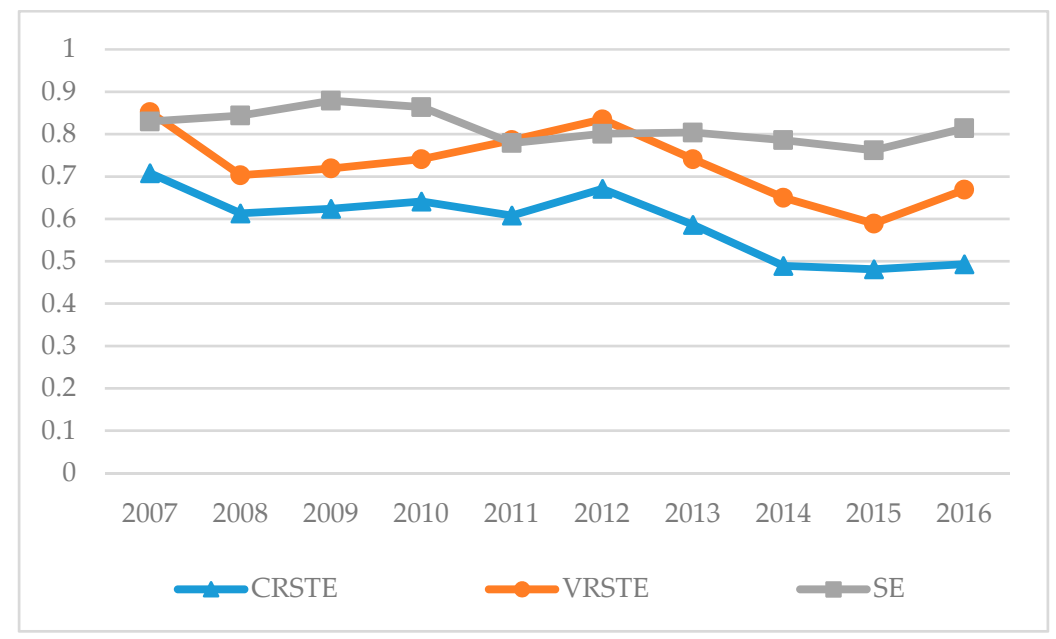

Figure 1. Decomposition of EGE in the Yangtze River urban agglomeration.

\subsubsection{Research on Spatial Differentiation of EGE}

Using OpenGeoDa software [25] (Tang and Zhang, 2008), take the average value of the EGE of the Yangtze River urban agglomeration from 2007 to 2016 as the reference, divide the efficiency value into three categories and plot in Figure 2a; Choose the EGE of the Yangtze River urban agglomeration in 2007, 2012, and 2016, respectively, as the reference, plot in Figure 2b-d. By analyzing the result of grade distribution (Figure 2), the average efficiency values in Nanjing, Changzhou, and Wuxi are from 0.742 to 0.934 , which are of high efficiency levels. The average value of efficiency in Yangzhou and Zhenjiang is between 0.423 and 0.698 , which is a typical efficiency level; the average efficiency of Taizhou, Nantong, and Suzhou is between 0.264 and 0.371, which is an inefficient level. In 2007, the EGE of the Yangtze River urban agglomerations was generally higher, with the indices of Nanjing, Zhenjiang, and Changzhou reaching 1 . This indicates that in 2007, the level of economic development was not high and the environmental pollution of each city was not serious. As a result, environmental governance is relatively effective. By 2012, Nantong and Taizhou were transformed from low efficiency to high efficiency, indicating that environmental management was emphasized in the process of urban development, and the EGE was improved, while Yangzhou and Zhenjiang became inefficient regions, indicating that the environmental pollution control was neglected during urban economic development process. In addition to Nanjing, Zhenjiang, and Yangzhou, in 2016, the efficiency of environmental management in other cities was lower than the average value, indicating that the Yangtze River urban agglomeration did not maintain the simultaneous development of environmental governance and economy in the process of economic development. The EGE of Nanjing has been at a relatively high level, indicating that its input and output have reached an optimized level; Yangzhou and Zhenjiang were promoted to high-efficiency areas in 2016, indicating that it may take the old pattern of "polluting first and cleaning up later", and environmental governance did not advance in a coordinated manner with urban construction. From a spatial perspective, the level of urban development in southern Jiangsu is relatively fast, and the EGE is also high; by contrast, the level of urban development in central Jiangsu is relatively slow and the EGE is relatively low. 

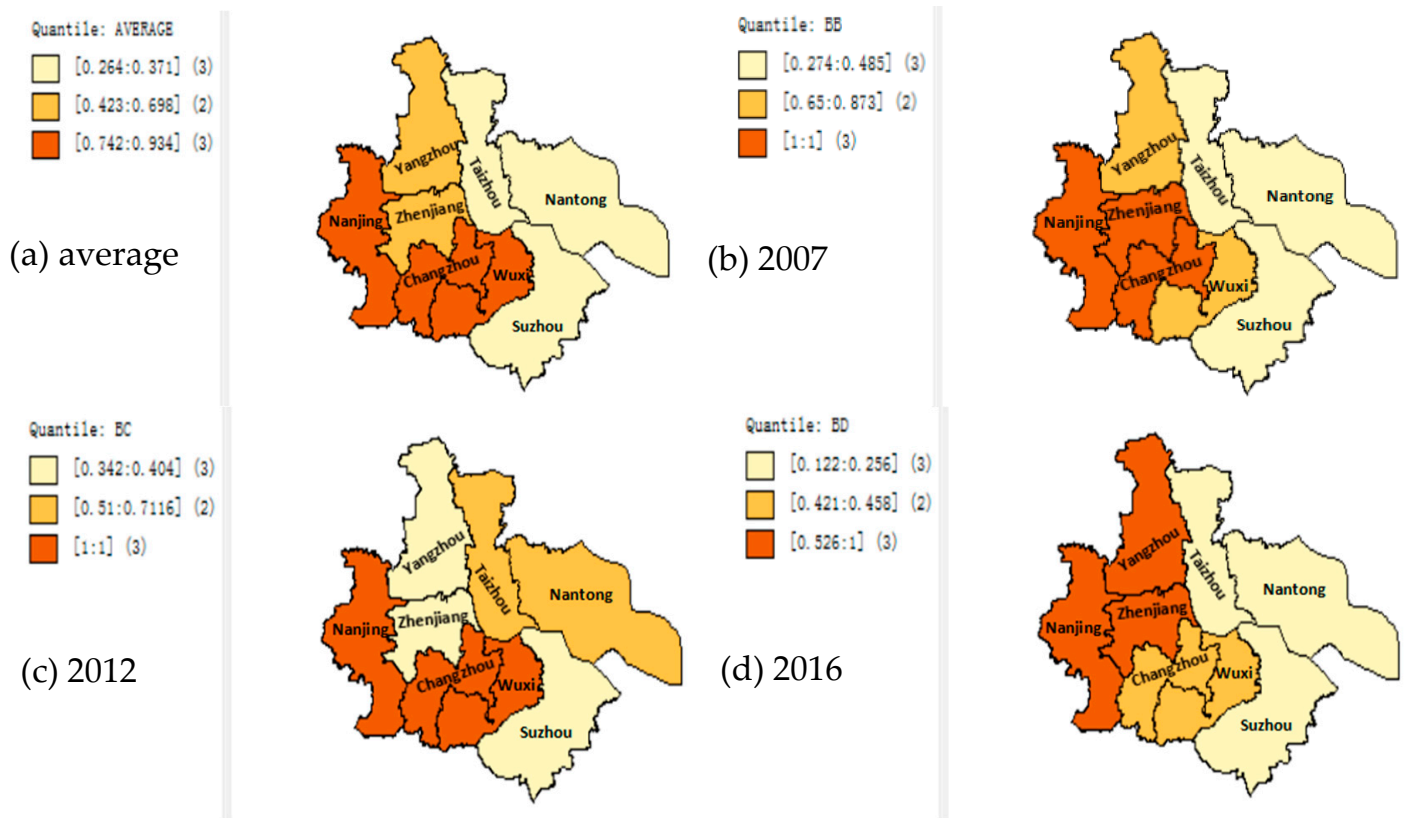

Figure 2. Distribution of EGE of the Yangtze River urban agglomeration. (a) Distribution of the average efficiency of the cities over 10 years; (b) Efficiency distribution of cities in 2007; (c) Efficiency distribution of cities in 2012; (d) Efficiency distribution of cities in 2016.

\subsection{Malmquist Analysis of EGE in the Yangtze River Urban Agglomeration}

Malmquist [26] (Malmquist, S. 1953) exponential decomposition is to decompose the efficiency change index (effch) into a technical efficiency change index (techch) and technological progress index (tfpch), and then decompose techch into a pure techch index (ptech) and scale efficiency change index (seffch). Ptech reflects the impact of technological level on productivity; scale efficiency change reflects the impact of scale economy on productivity and the proximity of DMU to the optimal scale; technological change reflects the impact of moving production frontiers on productivity. If effch, ptech, seffch, and techch are greater than one, this indicates that this indicator has a positive effect on EGE; if it is less than 1 , the opposite is true.

Through the analysis of the decomposition results (Table 5), the effch of Nanjing and Zhenjiang were greater than 1, which were 1.204 and 1.098 respectively, indicating that both cities have made progress in urban environmental governance. These two cities have increased by $20.4 \%$ and $9.8 \%$ respectively, mainly driven by technological progress, indicating that Nanjing and Zhenjiang have achieved good results in environmental governance technology over the past 10 years. The effch of the other six cities were all less than 1, which were 0.961 in Yangzhou, 0.921 in Taizhou, 0.924 in Changzhou, 0.989 in Wuxi, 0.896 in Suzhou, and 0.952 in Nantong, and the degree of regression in environmental governance was $1.1 \%$ to $10.4 \%$. Among them, Suzhou City had the most obvious step backwards for more than $10 \%$, mainly due to techch and seffch. This shows that although Suzhou is a major city for economic development in our province, it has not improved its environmental governance technical efficiency, and its economic scale has not developed rapidly. In order to harmonize environmental and economic development, Suzhou must pay attention to economic scale and technological efficiency. The decline of EGE in other 5 cities is not obvious. The main influencing factor is the level of technical efficiency. 
Table 5. Malmquist exponential decomposition results of EGE of the Yangtze River urban agglomeration from 2007 to 2016.

\begin{tabular}{cccccc}
\hline DMU & effch & techch & tfpch & ptech & seffch \\
\hline Nanjing & 1.20 & 1.00 & 1.20 & 1.00 & 1.00 \\
Zhenjiang & 1.09 & 1.00 & 1.09 & 1.00 & 1.00 \\
Yangzhou & 0.96 & 0.94 & 1.01 & 1.01 & 0.93 \\
Taizhou & 0.92 & 0.93 & 0.98 & 0.91 & 1.01 \\
Changzhou & 0.92 & 0.92 & 1.00 & 0.92 & 0.99 \\
Wuxi & 0.98 & 0.95 & 1.03 & 0.92 & 1.03 \\
Suzhou & 0.89 & 0.88 & 1.01 & 1.00 & 0.88 \\
Nantong & 0.95 & 0.92 & 1.03 & 0.89 & 1.02 \\
mean & 0.98 & 0.94 & 1.04 & 0.95 & 0.98 \\
\hline
\end{tabular}

Note: DMU refers to research decision unit (DU); effch refers to efficiency change index; techch refers to technological efficiency change index; ptech refers to pure technical efficiency change index; seffch refers to scale efficiency change index; tfpch refers to technological progress index.

From Figure 3, we found that technological progress is the main factor driving the improvement of the EGE; Cities with high tfpch universally have high EGE; Suzhou City is more special, as the city's tfpch is higher than others, but the EGE is lower, indicating that the degree of technological progress in Suzhou is lower than the degree of backwardness in technical efficiency and scale efficiency.

Through the analysis of technical progress index decomposition results (Figure 4), we found that, except for the seffch of Yangzhou, Changzhou, and Suzhou, which is lower than 1, the other cities are all greater than 1 and the ptech of each city is basically lower than 1 . This shows that scale efficiency change is the main factor that drives technological progress. Therefore, the improvement of urban EGE must make urban development closer to the optimal scale.

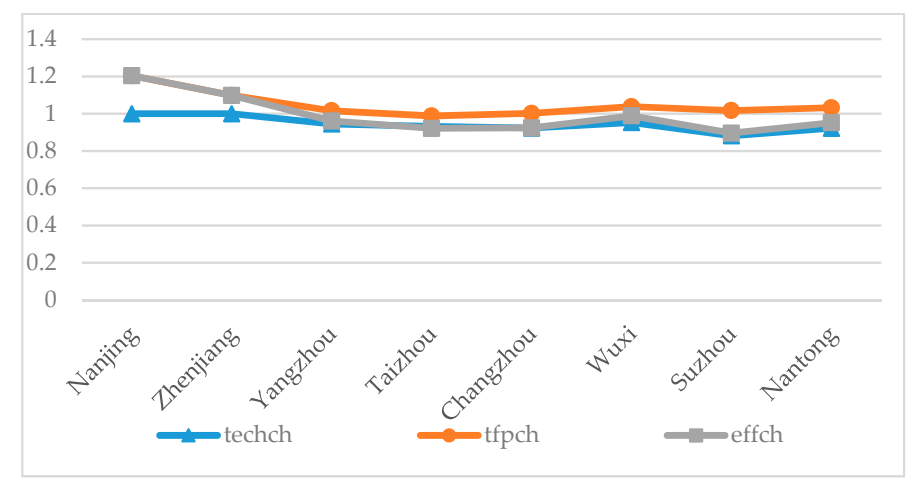

Figure 3. Efficiency change index and index decomposition of EGE of the Yangtze River urban agglomeration in 2007-2016.

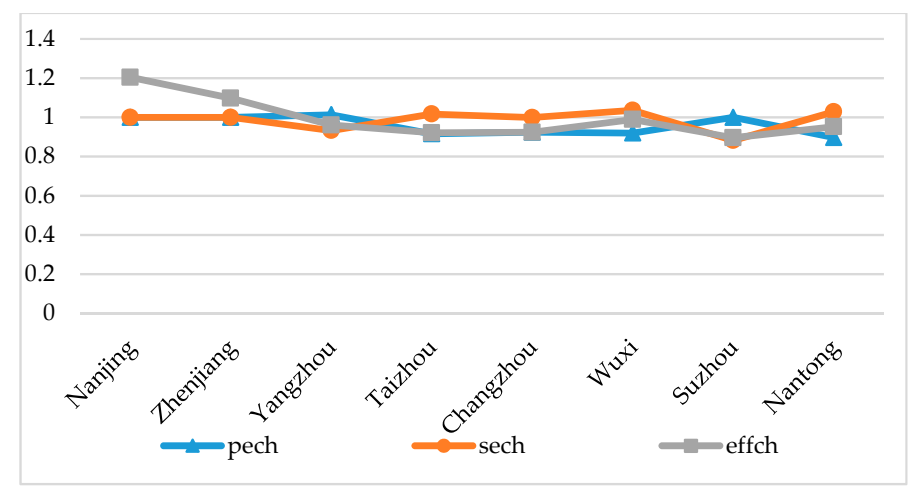

Figure 4. Index of efficiency change and index decomposition of EGE of the Yangtze River urban agglomeration in 2007-2016. 


\section{Influencing Factors of EGE}

After obtaining the calculation results from the DEA model, it was found that the EGE of the Yangtze River urban agglomeration is also affected by other factors, in addition to the output indicators. Therefore, we selected other indicators as the main influencing factors of EGE and analyzed the effects of these influencing factors on EGE using the Tobit regression model.

\subsection{Main Influencing Factors of EGE}

The EGE of the Yangtze River urban agglomeration, which was previously calculated using the DEA model, is also affected by other factors than the output indicators of Malmquist model. To further analyze the influencing factors of EGE, the aspects listed below are selected as the main influencing factors of EGE on the basis of development status of the Yangtze River urban agglomeration (Table 6):

Table 6. Factors affecting the EGE of the Yangtze River urban agglomeration.

\begin{tabular}{cccc}
\hline Explanatory Variable & Definitions and Units & Shorthand & Literature Basis \\
\hline The level of urbanization & Proportion of urban population (\%) & X1 & \\
Industrial structure & Tertiary industry share of GDP (\%) & X2 & Gai Mei et al. (2012) \\
Economic level & Per capita GDP (¥) & X3 & Wang Qin et al. [27] (2014) \\
Urban construction & Infrastructure investment (100 million ¥) & X4 & Wang Qing [28] (2015) \\
Population density & Population density (person/ sq.km.) & X5 & Song Yanan [29] (2012) \\
Capital openness & Actual use of foreign investment (10,000 \$) & X6 & \\
\hline
\end{tabular}

\subsection{Tobit Regression Study}

The Tobit regression model can be used to solve regressions with restricted conditions. The regression equation is given as follows [30,31] (Tobin, 1956; Coelli, 1998):

$$
\begin{gathered}
\mathrm{y}=\beta^{\prime} x i+u i, \\
y^{*}{ }_{i}=\mathrm{y}_{i}, \text { if } y^{*}{ }_{i}>0, \\
y^{*}{ }_{i}=0, \text { if } y^{*}{ }_{i} \leq 0 .
\end{gathered}
$$

In the Equation, $y_{i}^{*}$ is a potential variable, observed when the latent variable is greater than 0 , and the value is $y_{i}$, truncate at 0 when it is less than or equal to $0 ; X_{i}$ is an independent vector, $\beta$ is a coefficient vector, the error term $u_{i}$ is independent and obeys the normal distribution: $u_{i} \sim N\left(0, \sigma^{2}\right)$.

A metrology analysis software Eviews (Microsoft, Redmond, WA, USA) was used to make a unit root test; the indicators were brought into Eviews for Tobit regression (Table 7).

Table 7. Results of Tobit regression analysis on EGE influencing factors (1).

\begin{tabular}{ccccc}
\hline Variable & Coefficient & Std. Error & Z-Statistic & Prob. \\
\hline SER02 & -0.58 & 0.48 & -1.21 & 0.22 \\
SER03 & $4.19^{* * *}$ & 1.61 & 2.59 & 0.01 \\
SER04 & $-5.77 \times 10^{-6 * *}$ & $2.30 \mathrm{E}-06$ & -2.51 & 0.01 \\
SER05 & $-10.78^{* * *}$ & 2.52 & -4.26 & 0.00 \\
SER06 & $7.14 \times 10^{-5 *}$ & $4.19 \mathrm{E}-05$ & 1.70 & 0.08 \\
SER07 & $2.63 \times 10^{-7}$ & $1.96 \mathrm{E}-07$ & 1.34 & 0.18 \\
C & -0.38 & 0.37 & -1.01 & 0.30 \\
\hline
\end{tabular}

Note: SER01 = EGE, SER02 $=$ X1, SER03 $=$ X2, SER04 $=$ X3, SER05 $=$ X4, SER06 $=$ X5, SER07 $=$ X6. ${ }^{*} 10 \%$ of significance level, ${ }^{* *} 5 \%$ of significance level, ${ }^{* * *} 1 \%$ of significance level.

The Tobit regression results indicate that the significance of the urbanization level and capital openness has not passed the test, which is to say that its effect on the EGE is not very obvious. Therefore, removing both of them for Tobit regression again, we have obtained the following results (Table 8). 
Table 8. Results of Tobit regression analysis of influencing factors (2).

\begin{tabular}{ccccc}
\hline Variable & Coefficient & Std. Error & Z-Statistic & Prob. \\
\hline SER03 & $2.20^{* *}$ & 0.94 & 2.34 & 0.01 \\
SER04 & $-3.05 \times 10^{-6 *}$ & $1.66 \mathrm{E}-06$ & -1.8350 & 0.06 \\
SER05 & $-9.4962^{* * *}$ & 2.27 & -4.18 & 0.00 \\
SER06 & $6.52 \times 10^{-5 *}$ & $3.79 \mathrm{E}-05$ & 1.71 & 0.08 \\
C & -0.03 & 0.31 & -0.09 & 0.92
\end{tabular}

Note: SER01 refers to EGE; SER03 refers to factor X2; SER04 refers to factor X3; SER05 refers to factor X4; SER06 refers to factor X5. ${ }^{*} 10 \%$ of significance level; $* * 5 \%$ of significance level; $* * * 1 \%$ of significance level.

The economic development level and urban construction have an adverse effect on the EGE at the significant level of $10 \%$ and $1 \%$. For every $1 \%$ increase in per capita GDP, the EGE drops by $3.05 \times 10^{-6} \%$; for every $1 \%$ increase in investment in infrastructure construction, the EGE will decline by $9.496233 \%$. Industrial structure and population density have a favorable effect on the EGE at the significant level of $5 \%$ and $10 \%$, respectively. For every $1 \%$ boost in the GDP of the tertiary industry, the EGE will increase by $2.208085 \%$; for each $1 \%$ increase in population density, the EGE will increase by $6.52 \times 10^{-5} \%$.

\subsection{Analysis and Discussion of Results}

The economic development level and urban construction have an adverse effect on the EGE. However, the overall income level of the Yangtze River urban agglomeration is at the top of the country, but the EGE is at the middle-to-upper level. Although the income level increases, the ability to generate pollutants also increases, and the generated domestic garbage has not been properly disposed of, resulting in a decrease of urban EGE. That is, the ability to produce pollution has increased, but the awareness of protecting the urban environment has not been strengthened. With the increase of the construction for urban infrastructure, more pollutants will be generated and more resources will be needed to deal with them, which will inevitably reduce the urban EGE.

The industrial structure has a beneficial effect on the urban EGE. As an important developing area in Jiangsu province, the Yangtze River urban agglomeration has always been dominated by the tertiary industry. Suzhou and Nanjing are high-tech cities. Wuxi and Nantong mainly develop the textile industry. Therefore, vigorous improvement of the tertiary industry is conducive to the EGE. Additionally, the service industries, such as scientific research design, logistics industry, and financial industry in the tertiary industry, contribute to the positive effect of productivity and EGE. However, the low EGE in Suzhou is primarily affected by excessively invested on but inadequately utilized resources in environmental protection.

Population density has a beneficial effect on the urban EGE. Nanjing is the most obvious example. More and more laborers in other provinces are pouring into Nanjing, which greatly increases the population density of Nanjing. However, the EGE of Nanjing is the highest in the Yangtze River urban agglomeration. The reason is that the population density has brought about the improvement of living standards and education. The increase in education level, economic growth, and awareness of environmental protection should be greater than the environmental pressure. Therefore, large immigration numbers are in fact conducive to the improvement of urban EGE rather than having a negative effect.

The level of urbanization and the capital openness have no significant effect on the EGE of the Yangtze River urban agglomeration. This shows that in improving urban environmental governance measures, the level of urbanization and capital openness are not the main factors to consider. 


\section{Conclusions}

\subsection{Conclusions and Suggestions}

In general, the EGE of the Yangtze River urban agglomeration is relatively low. There are 4 cities with relatively high efficiency, namely Nanjing, Changzhou, Wuxi, and Zhenjiang, of which Nanjing has the highest efficiency, as high as $0.934 ; 4$ cities have relatively low efficiency, namely Yangzhou, Suzhou, Taizhou, and Nantong, of which Nantong has the lowest efficiency, as low as 0.246.

Judging from the time dimension, the overall EGE of the Yangtze River urban agglomeration is in the upper middle level. In 2007, the EGE reached its maximum value, and then the index gradually decreased. Since 2012, the EGE index has rapidly declined. In the course of economic development, we should improve the environmental management agencies and strengthen the management and supervision of urban environmental governance to ensure that the EGE is gradually improved, instead of promoting the development of urban economy at the expense of the environment.

Judging from the spatial perspective, the urban development in the southern part of Jiangsu is relatively fast, and the EGE is also high. The urban development in northern Jiangsu is relatively lagging behind, causing greater damage to the environment and a lower EGE. Therefore, it is necessary to construct the exchange system of the Yangtze River urban agglomeration with a shared concept, in order to achieve interconnection and interoperability among the eight cities, and to promote environmental governance in coordination.

According to the DEA-Malmquist index decomposition analysis, the EGE of the Yangtze River urban agglomeration is basically driven by tfpch, and the seffch is the main driver of tfpch. Suzhou and Nantong have invested much more in environmental governance than other cities, but the EGE is the last. The main reason is that environmental governance technology is not mature and capital investment has little effect. Therefore, it is particularly important to accelerate the development of science and technology. The Yangtze River urban agglomeration needs to improve technological innovation capabilities; accelerate the elimination of backward and immature environmental technologies; and communicate actively with other environmentally more efficient regions and introduce advanced environmental protection technologies.

From the Tobit regression research analysis, it is concluded that urbanization level and capital openness have no significant impact on urban EGE; the economic development level and urban construction have an adverse impact on urban EGE; and industrial structure and population density have a beneficial impact on urban EGE. Therefore, optimizing industrial structure during the development of the Yangtze River urban agglomeration has a positive effect on improving regional environmental quality. Transferring energy-intensive and highly-polluting enterprises to knowledge-intensive and environment-friendly industries can enhance the harmonious advancement of the economy and environment. In addition, the population density has a beneficial effect on the efficiency of urban environmental governance. Therefore, the government should encourage the public to join the environmental management, through the three-party supervision of the government, enterprises, and the public to promote the improvement of urban EGE.

\subsection{Study Limitations and Prospects}

Although we tried to select influencing factors comprehensively and systematically, it is inevitable to have some missed considerations and it is difficult to cover all the factors affecting the EGE. In addition, we have only studied the efficiency of China's interprovincial environmental governance from a macro perspective. Due to the lack of more specific industry characteristics, it is difficult to provide targeted policy recommendations for different industries. Therefore, the next step is to study the EGE of various industries, to explore the mechanism of environmental governance-influencing factors from a micro perspective, to provide a deeper industry foundation for China's EGE, and thus to formulate more practical policy guidance for microproducers. 
Author Contributions: Conceptualization, B.P.; Methodology, B.P.; Formal Analysis, B.P. and Y.L.; Investigation, Y.L.; Resources, B.P.; Data Curation, Y.L.; Writing-Original Draft Preparation, B.P. and Y.L.; Writing-Review \& Editing, G.W.; Visualization, G.W.; Supervision, B.P. and G.W.; Project Administration, B.P. and E.E.; Funding Acquisition, B.P.

Funding: The authors are grateful to the case company for permitting and supporting this research. This work was financially supported by HRSA, US DHHS (Grant No. H49MC00068), the National Natural Science Foundation of China (Grant No. 71263040, Grant No. 71563030), the Key Projects of Philosophy and Social Science for Universities in Jiangsu (Grant No. 2017ZDIXM119, Grant No. 2017ZDTXM007), the Social Science Foundation of Jiangsu (Grant No. 17GLD013, Grant No. 17DDA007), the Priority Academic Program Development of Jiangsu Higher Education Institutions (PAPD), the Top-Notch Academic Programs Project of Jiangsu Higher Education Institutions (TAPP), and Postgraduate Research and Practice Innovation Program of Jiangsu Province, and Start up Foundation for Introducing Talent of Nanjing University of Information Science and Technology (Grant No. 2017r101).Nanjing University of Information Science \& Technology Research Base of Socialism with Chinese Characteristics Theory System and Science Project (2018-7).

Conflicts of Interest: The authors declare no conflict of interest.

\section{References}

1. Gan, T.; Wang, Z.L. Measurement of urban environmental governance efficiency in the Yangtze River Delta. Urban Probl. 2018, 1, 81-88.

2. Zaim, O.; Taskin, F. Environmental efficiency in carbon dioxide emissions in the OECD: A non-parametric approach. J. Environ. Manag. 2000, 58, 95-107. [CrossRef]

3. Mandal, S.K.; Madheswaran, S. Environmental efficiency of the Indian cement industry: An interstate analysis. Energy Policy 2009, 10, 1108-1118.

4. Van Leeuwen, C.J.; Koop, S.H.A.; Sjerps, R.M.A. City Blueprints: Baseline assessments of water management and climate change in 45 cities. Environ. Dev. Sustain. 2016, 18, 1113-1128. [CrossRef]

5. Tang, X.X.; Zhang, H.Q.; Liu, R. Study on spatial correlation analysis of GDP in Liaoning province based on GeoDa. For. Res. 2008, S1, 60-64.

6. Reinhard, S.; Lovell, C.K.; Thijssen, G. Environmental efficiency with multiple environmentally detrimental variables; estimated with SFA and DEA. Eur. J. Oper. Res. 2000, 121, 287-303. [CrossRef]

7. Luo, Y. DEA-Based Research on Indicator Selection and Environmental Performance Measurement. Ph.D. Dissertation, University of Science and Technology, Hefei, China, 2012.

8. Tang, D.C.; Ping, S.; Zhong, F.X.; Li, C.S. Research on evaluation index system of low-carbon manufacturing industry. Energy Procedia 2012, 1, 541-546. [CrossRef]

9. Tu, Z.G.; Geng, R.J. Environmental technology efficiency of traditional method measurement underestimates the environmental governance efficiency?-Evidence from the analysis of provincial industrial panel data from directional environmental distance function method based on web DEA. Econ. Rev. 2013, 5, 89-99.

10. Kuosmanen, T.; Entertainer, M. Measuring Eco-efficiency of production with data envelopment analysis. J. Ind. Ecol. 2015, 9, 59-72. [CrossRef]

11. Koop, S.H.A. Assessing the governance capacity of cities to address challenges of water, waste, and climate change. J. Water Res. Manag. 2017, 31, 3427-3443. [CrossRef]

12. Gunningham, N. The new collaborative environmental governance: The localization of regulation. J. Law Soc. 2009, 36, 145-166. [CrossRef]

13. Tang, D.C.; Shen, Z.Q.; Li, C.S.; Chen, Y.M. Policies of developed countries and policy choices of china low-carbon manufacturing. Energy Procedia 2012, 1, 547-552. [CrossRef]

14. Bruce, R.D.; William, L.W. Does environmental protection lead to slower productivity growth in the chemical industry. Environ. Resour. Econ. 2004, 28, 301-324.

15. Kitagawa, H.; Geng, X. China's environmental law, environmental policy implementation, and improvement of environmental governance-Focusing on local governments. Contemp. Jpn. Stud. Chin. 2017, 40, 7-13.

16. Tang, L.M. Japan's Refined Environmental Governance and Its Enlightenment to China. Master's Thesis, Shandong University, Jinan, China, 2017.

17. Charnes, A.; Cooper, W.W.; Rhodes, E. Measuring the efficiency of decision making units. Eur. J. Oper. Res. 1978, 3, 429-444. [CrossRef]

18. Fare, R.; Grosskopf, S. Measuring output efficiency. Eur. J. Oper. Res. 1986, 13, 173-179. [CrossRef] 
19. Huppes, G.; Ishikawa, M. A framework for quantified eco-efficiency analysis. J. Ind. Ecol. 2005, 9, $25-41$. [CrossRef]

20. Wang, J.N.; Xu, Z.C.; Hu, X.B.; Peng, X.C.; Zhou, Y. Analysis of regional environmental efficiency in China based on DEA theory. Chin. J. Environ. Sci. 2010, 30, 565-570.

21. Guo, G.F.; Zheng, Z.F. Evaluation of environmental governance efficiency based on DEA Model—Taking Henan as an example. Econ. Probl. 2009, 1, 48-51.

22. Gai, M.; Lian, D.; Tian, C.S.; Ke, L.N. Liaoning province's environmental efficiency and its temporal and spatial variations. Geogr. Res. 2014, 33, 2345-2357.

23. Li, M. Evaluation of the Efficiency of Industrial Production and Environmental Governance in China and its Interaction with Foreign Trade. Master's Thesis, Hefei University of Technology, Hefei, China, 2017.

24. Wu, H.Q.; Shi, Y.; Xia, Q.; Zhu, W.D. Effectiveness of the policy of circular economy in China: A DEA-based analysis for the period of 11th five-year-plan. Resour. Conserv. Recycl. 2014, 83, 163-175. [CrossRef]

25. Tang, D.C.; Tang, J.X.; Zheng, X. Environmental regulation efficiency and total factor productivity-Effect analysis based on Chinese data from 2003 to 2013. Ecol. Indic. 2016, 73, 312-318. [CrossRef]

26. Malmquist, S. Index numbers and indifference surfaces. Trab. Estad. 1953, 4, 209-242. [CrossRef]

27. Wang, Q.; Guo, F.; Xu, X.Y.; Li, W.W. Assessment of urban environmental governance efficiency and its spatial and temporal variation in China. Geogr. Res. 2012, 21, 153-162.

28. Wang, Q. Study on Jiangsu Environmental Management Efficiency Evaluation and Influencing Factors. Master's Thesis, Southeast University, Nanjing, China, 2015.

29. Song, Y.N. Research on Industrial Environmental Efficiency of Coastal Economic Belt in Liaoning Province. Master's Thesis, University of Chinese Academy of Sciences, Beijing, China, 2012.

30. Tobin, J. Estimation of relationships for limited dependent variables. J. Econ. Soc. 1958, 26, 24-36. [CrossRef]

31. Coelli, T. A multi-stage methodology for the solution of orientated DEA models. J. Oper. Res. Lett. 1998, 23, 143-149. [CrossRef]

(C) 2018 by the authors. Licensee MDPI, Basel, Switzerland. This article is an open access article distributed under the terms and conditions of the Creative Commons Attribution (CC BY) license (http:// creativecommons.org/licenses/by/4.0/). 